\title{
The Influence of Social Crowding on Consumer Creativity
}

\author{
Luqiong Tong ${ }^{1} \&$ Jing $\mathrm{Li}^{1}$ \\ ${ }^{1}$ Business School, Beijing Normal University, Beijing, China \\ Correspondence: Luqiong Tong, Business School, Beijing Normal University, Beijing, China. E-mail: \\ tonglq@bnu.edu.cn
}

Received: August 9, 2021

doi:10.5539/ijbm.v16n11p26
Accepted: September 10, 2021

Online Published: September 21, 2021

\begin{abstract}
The importance of consumer creativity is currently widely recognized, yet the examination of the influence of environmental elements on consumer creativity is still limited. Our research investigates the influence of social crowding on consumer creativity performance. While past research mainly focuses on extreme crowding conditions, our research examines the impact of a moderate level of social crowding, which is more commonly experienced in reality. From two lab experiments, our research shows that compared to consumers in crowded environments, consumers in uncrowded environments perform better on creativity tasks (e.g., designing promotion slogans and identifying solutions to problems). Furthermore, the effect of social crowding is mediated by approach motives. Consumers in an uncrowded (vs. crowded) environment are more likely to trigger approach-based motivation, which enhances their creativity performance. These findings extend our knowledge of social crowding and creativity and can help consumers and companies improve creativity performance in appropriate environments.
\end{abstract}

Keywords: social crowding, approach motive, consumer creativity

\section{Introduction}

\subsection{Creativity and Social Crowding}

Creativity is currently playing an increasingly important role. Many consumers have begun to design their own dresses and shoes, play kits in their leisure time, or even help companies generate ideas for their products and communications. Creative consumers are more likely to enjoy the consumption experience; to experience a greater sense of accomplishment, satisfaction and pride from everyday life; and to adopt new and innovative products (Harrison, 2016). Companies have also tried to make use of creativity by crowdsourcing and providing self-generating products or services. Creativity is crucial for companies' survival when it determines the quality of new product development and brand value (Mehta et al., 2017). Creativity also advances the improvement of society as a whole (Mehta \& Dahl, 2019).

Given the importance of creativity, much research has explored the factors that influence creativity, such as personal traits (e.g., intelligence; Albert \& Runco, 1999), thinking abilities (e.g., analogical reasoning; Dahl \& Moreau, 2002), emotions (Trujillo \& Rosa, 2017), motivation (Amabile, 1996), cultural differences (Maddux \& Galinsky, 2009), task characteristics (Moreau \& Dahl, 2005), external rewards (Mehta, Dahl, \& Zhu, 2017), and environmental stimuli (Van den Bergh et al., 2008). Although scholars have noted that the social environment may influence creativity, few researchers have examined the effects of environmental elements such as background noise (Mehta et al., 2012), order (Vohs et al., 2013), and darkness (Steidle et al., 2013) on consumers' creativity performance (Zhu \& Mehta, 2017).

However, among the studies proving environmental factors to have an impact on creativity, only a few have discussed the influence of social crowding on creativity (Maeng et al., 2017), and this area also suffers from several limitations. First, past research has examined extreme conditions of social crowding (e.g., too many people in a room), which significantly change participants' arousal levels but are not commonly experienced in our real life. Furthermore, past research has only demonstrated the basic effects of social crowding and some moderators while not illustrate the underlying mechanisms involved. Therefore, this research aims to examine whether and how more typical social crowding conditions, which do not affect people's moods and arousal levels, may influence consumer creativity, and in turn attempts to uncover the underlying mechanism of the influence of social crowding. 


\subsection{Literature and Hypothesis}

Social crowding is defined as physical proximity to others in a confined area (Stokols 1972). Because restricting personal space is often aversive, social crowding can have certain consequences. For example, consumers in crowded environments are more likely to experience negative emotions, stress and a loss of personal control (Evans \& Wener, 2007), and they seek ways to restore control by, for example, variety seeking (Levav \& Zhu, 2009) and engaging in more word-of-mouth communication (Consiglio et al., 2018). Crowded individuals may also avoid further social interactions and develop a lower preference for interaction-oriented anthropomorphized brands (Puzakova \& Kwak, 2017) but form a stronger attachment to other kinds of brands (Huang et al., 2018).

Moreover, social crowding also affects consumers' information processing and decision making. For example, individuals in socially crowded environments tend to rely more on concrete (vs. abstract) level of construal (Maeng \& Tanner, 2013) and to adopt more affective processing, which in turn increases their calorie consumption (Hock et al., 2018). Of particular relevance to our research is the fact that as crowding impedes personal space, it activates the human defense system. For example, social crowding reduces exploratory behavior in stores and triggers risk avoidance (Harrell et al., 1980). Maeng et al. (2013) found that people who are socially crowded were more likely to develop a prevention focus and hence prefer safety-oriented choice options, engage in actual prevention-oriented behaviors and are more easily persuaded by prevention-framed messages. For example, consumers who were presented with crowded (vs. uncrowded) pictures reported higher prevention scores, and then influences their preferences toward choice options with safety connotation. Xu and Albarracin (2016) also showed that constrained spaces enhance consciously controlled motor and social behaviors. To summarize, social crowding activates prevention- and inhibitory-based mindsets where people in less crowded environments are more willing to take risks and develop approach-based motivation.

Given that the avoidance system constricts the span of conceptual and perceptual attention, it forms a more tightly focused mental representation, but the approach system is more likely to activate remote associations and explorative thinking. Past research has shown that compared to avoidance motivation, approach motivation is more beneficial for creativity (Frideman \& Förster, 2005). For example, approach (vs. avoidance) gestures enhance creative insight (Cretenet \& Dru, 2009), and exposure to colors that induce approach (e.g., blue) versus avoidance motivation (e.g., red) enhance creativity performance (Mehta \& Zhu, 2009). Moreover, Roskes et al. (2012) showed that approach motivation encourages cognitive flexibility and that avoidance motivation increases cognitive persistence, showing that the former is more beneficial for creative thinking and the latter is harmful for creativity. In combining these two lines of research, we suggest that compared to those in socially crowded environments, consumers in uncrowded environments are more likely to adopt approach (vs. avoidance) motives, which facilitate their creative performance. Thus, the following hypotheses are proposed:

H1: Consumers in socially uncrowded (vs. crowded) environments perform better on creativity tasks.

H2: Consumers in socially uncrowded (vs. crowded) environments are more likely to form approach-based (vs. avoidance-based) motives, which improve their creativity.

This research conducted two lab studies to test the hypothesis that an uncrowded (vs. crowded) environment is beneficial for consumer creativity. Study 1 studied a moderate level of social crowdedness and examined creativity differences across different levels of crowdedness. Study 2 replicated what the findings in Study 1 and examined the underlying mechanism of the impact of social crowding.

\section{Method and Results}

\subsection{Study 1}

The purpose of study 1 was to examine whether social crowding affects creativity.

\subsubsection{Participants and Procedure}

A total of 73 participants from an Asian university ( $55 \%$ female; $\left.M_{\mathrm{age}}=20.49, S D=1.92\right)$ participated in the study in exchange for monetary payment. The study applied a 2 condition (crowded vs. uncrowded) between subject design. Participants were randomly assigned to either a crowded (10-12 people in a room) or an uncrowded (2 people in a room) condition. The participants were told that the Chinese government wanted to add chopsticks to the country's world heritage list, and they were invited to generate slogans for chopsticks. No examples were given, and the participants had unlimited time to generate as many slogans as they desired.

After the participants listed their slogans, they were asked to report their current mood state on six items (happy, sad, excited, depressed, positive, and negative) on a scale of 1 (not at all) to 7 (very much). The items were averaged to create an overall mood index $(\alpha=.67)$ with higher numbers indicating a more positive mood. 
Participants also indicated their current level of arousal on three items (i.e., anxiety, comfortable, and calm) on a scale of 1 (not at all) to 7 (very much). The latter two items were reverse-coded, and the three items were then averaged to create an arousal index $(\alpha=.65)$. Next, as a manipulation check, the participants were asked to report their perception of a room's crowdedness on a scale of 1 to 7 (crowdedness, social density, distance to people nearby; $1=$ uncrowded, low density, and far, $7=$ crowded, high density, and near; $\alpha=.95$; the values were averaged to create a crowded rating index). Finally, the participants were asked to guess the true purpose of the study and to provide some demographic information.

\subsubsection{Results and Discussion}

Manipulation Check. No participant correctly guessed the purpose of the study, so the full sample was included in the analysis. Participants in the crowded condition reported feeling more crowded than those in the uncrowded $\operatorname{room}\left(M_{\text {crowded }}=4.83, S D=1.21 ; M_{\text {uncrowded }}=1.50, S D=.59 ; t(71)=14.45, p<.001\right)$.

Mood and Arousal. The results showed that mood and arousal levels were not significantly different between crowded and uncrowded conditions ( $p s>.79)$.

Creativity Performance. To analyze the key dependent variable, this research followed prior research (Dijksterhuis \& Meurs, 2006) in coding each participant's responses into two categories: (1) the number of slogans for chopsticks created and (2) the mean creativity score. For the first category, we counted the number of ideas each participant listed. We then recruited 12 judges from the same population as that of the study participants to rate the creativity of each slogan on an 11-point Likert scale $(0=$ "not at all creative," $5=$ "neither creative nor uncreative," and $10=$ "very creative"; $\alpha=.84$ ). We averaged the judges" ratings to obtain a mean creativity score for each idea, and then calculated each participant's mean creativity score by summing the mean creativity scores for all the ideas the participant generated and dividing the resulting number by the total number of ideas he or she generated.

A one-way ANOVA revealed a nonsignificant main effect of temperature on the total number of slogans generated $\left(M_{\text {crowded }}=1.95, S D=.81\right.$ vs. $\left.M_{\text {uncrowded }}=1.94, S D=.93, F(1,71)=.003, p>.96\right)$. However, as anticipated, the one-way ANOVA on the mean creativity score revealed a significant main effect $(F(1,71)=$ $5.91, p<.05$ ) such that participants in the uncrowded (vs. crowded) condition produced slogans rated as more creative $\left(M_{\text {crowded }}=3.37, S D=.98\right.$ vs. $\left.M_{\text {uncrowded }}=3.92, S D=.95\right)$.

Table 1. Number of slogans generated and creativity score in Study 1

\begin{tabular}{lll}
\hline Condition & Number of Ideas Generated & Creativity Rating \\
\hline Crowded & $1.95(.81)$ & $3.37(.98)$ \\
Uncrowded & $1.94(.93)$ & $3.92(.95)$ \\
\hline
\end{tabular}

The results of Study 1 revealed that compared to people in crowded environments, people in uncrowded environments performed better on creativity tasks, supporting H1. In the following study, we aimed to replicate this finding in a new task (generating ideas to solve problems), and more importantly, to uncover the underlying mechanism of the influence of crowding on creativity.

\subsection{Study 2}

The purpose of this study was to test $\mathrm{H} 2$, which proposes that social crowding decreases creativity performance due to approach-based motives.

\subsubsection{Participants and Procedure}

A total of 66 students from an Asian university $\left(60 \%\right.$ female; $\left.M_{\text {age }}=21.03, S D=2.29\right)$ participated in the study in exchange for monetary payment. As for Study 1, Study 2 applied a 2 condition (crowded vs. uncrowded) between subject design by manipulating the number of participants in a room ( 2 people vs. 10-12 people).

Participants completed the mood, arousal, and crowding-perception measures adopted in Study 1 and worked on a problem-solving task. The task description and instructions were as follows: "In China, many pedestrians cross streets/roads without paying attention to traffic or traffic lights, which causes severe problems for public safety. Please suggest some strategies to address this situation." No examples were provided, and the participants were given unlimited time to generate ideas. To encourage diligent work on the task, participants were told that the person whose idea was given the highest creativity rating would receive a $\$ 10$ reward from the researcher.

After completing the problem-solving task, participants answered the questions about the approach-based 
motivation (e.g., "I'd rather run my own business and take my own mistakes than listen to someone else's orders", "I enjoy having control of my own destiny"; Burger \& Cooper, 1979; $\alpha=.80$ ). Finally, participants were asked to guess the true purpose of the study and to provide demographic information.

\subsubsection{Results and Discussion}

Manipulation Check. No participant correctly guessed the purpose of the study, so the full sample was included in the analysis. Participants in the crowded condition reported feeling more crowded than those in the uncrowded $\operatorname{room}\left(M_{\text {crowded }}=4.56, S D=1.41 ; M_{\text {uncrowded }}=1.32, S D=.36 ; t(64)=12.76, p<.001\right)$.

Mood and Arousal. The results showed that mood and arousal levels were not significantly different between crowded and uncrowded conditions ( $p s>.60)$.

Creativity Performance. To analyze the key dependent variable, the same procedure in Study 1 was adopted by analyzing each participant's responses on two categories: (1) the number of ideas generated and (2) the mean creativity score. A one-way ANOVA revealed a nonsignificant main effect of temperature on the total number of slogans generated $\left(M_{\text {crowded }}=3.39, S D=.75\right.$ vs. $\left.M_{\text {uncrowded }}=3.67, S D=1.05 ; F(1,64)=1.48, p>.23\right)$. Moreover, an analysis of the mean creativity score revealed a significant main effect $(F(1,64)=11.84, p<.001)$ such that participants in the uncrowded (vs. crowded) condition produced more creative ideas $\left(M_{\text {crowded }}=4.18, S D=.86\right.$ vs. $\left.M_{\text {uncrowded }}=4.85, S D=.72\right)$.

Mediation of Approach Motivation. As expected, participants in the uncrowded environment showed higher levels of approach motivation $\left(M_{\text {crowded }}=4.41, S D=1.09\right.$ vs. $M_{\text {uncrowded }}=5.08, S D=1.09 ; F(1,64)=6.15, p$ $<.05$ ). To test the mediation effect of approach motivation, this research used model 4 of Hayes's (2017) process macro. Using social crowding as the independent variable, the mean creativity score as the dependent variable, and approach motivation as the mediator and following Preacher and Hayes (2004), we used 5,000 iterations to derive a $95 \%$ confidence interval (CI) for the indirect effect. The results showed a significant indirect effect of approach motivation (indirect effect $=-.1381 ; 95 \% \mathrm{CI}$ : $-.3401,-.0123$ ), supporting hypothesis 2 .

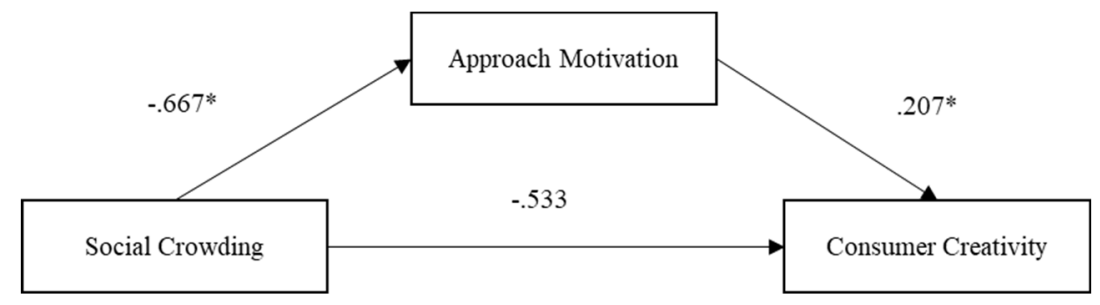

Figure 1. Mediation of approach motivation in Study 2

The results of Study 2 confirmed our hypothesis on why social crowding influences creativity when people in an uncrowded environment exhibit more approach motivation, which in turn benefits their creativity performance. Moreover, mood and arousal couldn't explain the effect of social crowding.

\section{Discussion}

While the importance of consumer creativity is acknowledged by researchers and companies, the examination of common factors that influence creativity is still limited, especially for the impact of environmental elements. In our research, we investigate whether and how a usual environmental factor-social crowding - affects consumer creativity. Overall, the results are as follows:

1) By comparing consumers' creativity performance on a slogan generating task, we find that compared to those in a crowded environment, consumers in an uncrowded environment are significantly more creative.

2) An uncrowded (vs. crowded) environment is more likely to trigger approach motives, which enhance consumer creativity, and thus mood and arousal cannot explain the effect of social crowding.

\subsection{Implications for Academic Research}

Our findings extend previous research in many ways.

First, as we have argued, there have been few discussions on the influence of social crowding on creativity in past research, and past work has also suffered from several limitations. On the one hand, the social crowding conditions adopted in past research have been rather extreme, causing changes in mood and arousal. In our research, we examine the impact of a more commonly experienced social crowding level on creativity performance without causing significant variations in mood and arousal. On the other hand, while past research 
only showed the basic effect, our research illustrates the mediation effect of approach motivation, which deepens our understanding of the impact of social crowding.

Second, these findings also add a new dimension to research on creativity, which has to date only covered a limited number of environmental factors (Mehta \& Dahl, 2019). The current research examines the influence an commonly experienced environmental factor-social crowding on consumer creativity, which extends our understanding of creativity.

Third, by revealing the mediation effect of approach motives, the current research enriches the knowledge of the motives induced by context and how they influence cognitive performance.

\subsection{Managerial Implications}

Our research also provides important implications for individuals and companies. As creativity increases consumption satisfaction and enjoyment, according to our research, consumers who want to improve their consumption experiences and performance could engage in an appropriate social crowding environment to enhance their creativity. Many companies today are increasingly relying on crowdsourcing and on designing products or services that encourage consumer creativity (e.g., mass-customization toolkits and self-generating products; Turner, Merle, \& Gotteland, 2020), and workers' creativity is rather critical for companies' development and even for their survival. Therefore, when planning an environment that supports creative work, companies should take the effects of social crowding into consideration.

\subsection{Limitations and Future Directions}

Future research would extend our research in many ways. First, the measurement of creativity includes two dimensions: whether it is innovative and whether it is practical. In our research, we mainly focus on the innovation aspect but do not measure the practicality of the ideas generated. Would it possible that social crowding decrease idea innovation but increase idea practicality? Second, according to prior research, the composition of the social crowd moderates the influence of social crowding. For example, Stokols (1972) suggested that when relationships with the crowding group is friendly, the limitations of crowding become less salient. It would thus be interesting to examine whether a crowd's composition also moderates its impact on creativity. We hope that the current research will trigger further examination of this important topic.

\section{References}

Albert, R. S., \& Runco, M. A. (1999). A history of research on creativity. In Robert J. Sternberg (Eds.), Handbook of creativity ( $p p$. 16-34). Cambridge, UK: Cambridge University Press.

Amabile, T. M. (1996). Creativity in context. Boulder, CO: Westview Press.

Burger, J. M., \& Cooper, H. M. (1979). The desirability of control. Motivation and Emotion, 3(4), 381-393. https://doi.org/10.1007/bf00994052

Consiglio, I., De Angelis, M., \& Costabile, M. (2018). The effect of social density on word of mouth. Journal of Consumer Research, 45(3), 511-528. https://doi.org/10.1093/jcr/ucy009

Cretenet, J., \& Dru, V. (2009). Influence of peripheral and motivational cues on rigid-flexible functioning: Perceptual, behavioral, and cognitive aspects. Journal of Experimental Psychology: General, 138(2), 201-217. https://doi.org/10.1037/a0015379

Dahl, D. W., \& Moreau, C. P. (2002). The influence and value of analogical thinking during new product ideation. Journal of Marketing Research, 39, 47-60. https://doi.org/10.1509/jmkr.39.1.47.18930

Dijksterhuis, A., \& Meurs, T. (2006). Where creativity resides: The generative power of unconscious thought. Consciousness and cognition, 15(1), 135-146. https://doi.org/10.1016/j.concog.2005.04.007

Evans, G. W., \& Wener, R. E. (2007). Crowding and personal spatial invasion on the train: Please don't make me sit in the middle. Journal of Environmental Psychology, 27(1), 90-94. https://doi.org/10.1016/j.jenvp.2006.10.002

Friedman, R. S., \& Förster, J. (2005). Effects of motivational cues on perceptual asymmetry: Implications for creativity and analytical problem solving. Journal of Personality and Social Psychology, 88(2), 263. https://doi.org/10.1037/0022-3514.88.2.263

Harrell, G. D., Hutt, M. D., \& Anderson, J. C. (1980). Path analysis of buyer behavior under conditions of crowding. Journal of Marketing research, 17(1), 45-51. https://doi.org/10.1177/002224378001700105

Harrison, S. (2016). Fueling, curating, connecting and fascinating: Why and how creativity provokes curiosity. 
In Capitalizing on Creativity at Work. Edward Elgar Publishing.

Hayes, A. F. (2017). Introduction to mediation, moderation, and conditional process analysis: A regression-based approach. Guilford publications.

Hock, S. J., \& Bagchi, R. (2018). The impact of crowding on calorie consumption. Journal of Consumer Research, 44(5), 1123-1140. https://doi.org/10.1093/jcr/ucx088

Huang, X., Huang, Z., \& Wyer Jr, R. S. (2018). The influence of social crowding on brand attachment. Journal of Consumer Research, 44(5), 1068-1084. https://doi.org/10.1093/jcr/ucx087

Levav, J., \& Zhu, R. (2009). Seeking freedom through variety. Journal of Consumer Research, 36(4), 600-610. https://doi.org/10.1086/599556

Maddux, W. W., \& Galinsky, A. D. (2009). Cultural borders and mental barriers: The relationship between living abroad and creativity. Journal of Personality and Social Psychology, 96, 1047-1061. https://doi.org/10.1037/a0014861

Maeng, A., \& Tanner, R. J. (2013). Construing in a crowd: The effects of social crowding on mental construal. Journal of Experimental Social Psychology, 49(6), 1084-1088. https://doi.org/10.1016/j.jesp.2013.07.010

Maeng, A., Tanner, R. J., \& Soman, D. (2013). Conservative when crowded: Social crowding and consumer choice. Journal of Marketing Research, 50(6), 739-752. https://doi.org/10.1509/jmr.12.0118

Maeng, A., Tanner, R. J., Wu, K., Ding, Y., Zhu, M., Wan, E. W. \& Yim, C. K. B. (2017). Beyond the Negative Consequences of Crowding: New Psychological Processes and Behavioral Outcomes. Advances in Consumer Research, 45, 243-244.

Mehta, R., \& Dahl, D. W. (2019). Creativity: Past, present, and future. Consumer Psychology Review, 2(1), 30-49. https://doi.org/10.1002/arcp.1044

Mehta, R., Dahl, D. W., \& Zhu, R. J. (2017). Social-recognition versus financial incentives? Exploring the effects of creativity-contingent external rewards on creative performance. Journal of Consumer Research, 44(3), 536-553. https://doi.org/10.1093/jcr/ucx062

Mehta, R., \& Zhu, R. J. (2009). Blue or red? Exploring the effect of color on cognitive task performances. Science, 323(5918), 1226-1229. https://doi.org/10.1126/science.1169144

Mehta, R., Zhu, R., \& Cheema, A. (2012). Is noise always bad? Exploring the effects of ambient noise on creative cognition. Journal of Consumer Research, 39, 784-799. https://doi.org/10.1086/665048

Moreau, C. P., \& Dahl, D. W. (2005). Designing the solution: The impact of constraints on consumers' creativity. Journal of Consumer Research, 32, 13-22. https://doi.org/10.1086/429597

Preacher, K. J., \& Hayes, A. F. (2004). SPSS and SAS procedures for estimating indirect effects in simple mediation models. Behavior Research Methods, Instruments, \& Computers, 36(4), 717-731. https://doi.org/10.3758/bf03206553

Puzakova, M., \& Kwak, H. (2017). Should anthropomorphized brands engage customers? The impact of social crowding on brand preferences. Journal of Marketing, 81(6), 99-115. https://doi.org/10.1509/jm.16.0211

Roskes, M., De Dreu, C. K., \& Nijstad, B. A. (2012). Necessity is the mother of invention: avoidance motivation stimulates creativity through cognitive effort. Journal of Personality and Social Psychology, 103(2), 242-256. https://doi.org/10.1037/a0028442

Steidle, A., \& Werth, L. (2013). Freedom from constraints: Darkness and dim illumination promote creativity. Journal of Environmental Psychology, 35, 67-80. https://doi.org/10.1016/j.jenvp.2013.05.003

Stokols, D. (1972). On the distinction between density and crowding: Some implications for future research. Psychological Review, 79 (3), 275-277. https://doi.org/10.1037/h0032706

Trujillo, C. A., \& Rosa, J. A. (2017). Consumer creativity influenced by hope, integral emotions and socio-economic status. International Journal of Consumer Studies, 41(5), 576-586. https://doi.org/10.1111/ijcs.12369

Turner, F., Merle, A., \& Gotteland, D. (2020). Enhancing consumer value of the co-design experience in mass customization. Journal of Business Research, 117, 473-483. https://doi.org/10.1016/j.jbusres.2020.05.052

Van den Bergh, B., Dewitte, S., \& Warlop, L. (2008). Bikinis instigate generalized impatience in intertemporal choice. Journal of Consumer Research, 35, 85-97. https://doi.org/10.1086/525505 
Vohs, K. D., Redden, J. P., \& Rahinel, R. (2013). Physical order produces healthy choices, generosity, and conventionality, whereas disorder produces creativity. Psychological Science, 24, 1860-1867. https://doi.org/10.1177/0956797613480186

Xu, A. J., \& Albarracín, D. (2016). Constrained physical space constrains hedonism. Journal of the Association for Consumer Research, 1(4), 557-568. https://doi.org/10.1086/688222

Zhu, R., \& Mehta, R. (2017). Sensory experiences and consumer creativity. Journal of the Association for Consumer Research, 2(4), 472-484. https://doi.org/10.1086/693161

\section{Copyrights}

Copyright for this article is retained by the author(s), with first publication rights granted to the journal.

This is an open-access article distributed under the terms and conditions of the Creative Commons Attribution license (http://creativecommons.org/licenses/by/4.0/). 